Chapter 27

\title{
Preparation, Physicochemical Properties and Battery Applications of a Novel Poly(Ionic Liquid)
}

\author{
Takaya Sato, Takashi Morinaga and Takeo Ishizuka \\ Additional information is available at the end of the chapter \\ http://dx.doi.org/10.5772/51162
}

\section{Introduction}

Ionic liquids (ILs) are generally defined as a salt with a melting point lower than $100{ }^{\circ} \mathrm{C}$ whose properties include non-volatility, non-flammability, and a relatively high ionic conductivity [1]. Recently, therefore, interest has increased in the possible use of this type of liquid as an electrolyte in energy storage devices, for example, a lithium rechargeable battery [2-9] and an electric double layer capacitor [10-14].

At the same time, to further the development of large, thin, prismatic electrochemical devices for which there is a high market demand, solid electrolytes are generally preferred over liquid electrolytes from the view point of ease of production and long device lifetime. In the last decade, many researchers and battery companies have been developing a "solid state polymer electrolyte" or a "gel polymer battery" with a film-like shape. More recently, growing attention has been paid to poly(ionic liquids) as a class of polymeric materials that are highly non-flammable. Examples of new polyelectrolytes poly(ILs) have been produced from polymerizable ionic liquid monomers by several polymerization processes. Research into the application of poly(ILs) for polymer electrolytes were under intense study by Ono et al around at 2005 [15-17]. The ensuing intensive studies on poly(ILs) in the last five years significantly expanded the research scope of this new type of polymer, and some valuable review [18-19] and feature articles have been published [20].

Amid such developments, we also developed a polymerizable ionic liquid, $\mathrm{N}, \mathrm{N}$-diethyl- $\mathrm{N}$ (2-methacryloylethyl)- $N$-methylammonium bis(trifluoromethylsulfonyl)imide (DEMMTFSI, whose molecular structure is shown in Fig.1). From many previous studies, it was known that aliphatic quaternary ammonium based ionic liquids had an obviously higher cathodic stability than the aromatic type ionic liquids. Therefore, polymer materials made from these polymerizable ILs could have high durability in use as an electrolyte in various 
energy devices. However, because there have been only a few reports on this topic, we describe in this chapter the preparation, polymerization, physicochemical properties, and the application of quaternary ammonium type polymerizable ionic liquids and related polymers.

On the other hand, the use of ILs as the solvent in free radical polymerization media instead of a conventional organic solvent markedly affects the rate and degree of polymerization. It has been reported that poly(methylmethacrylate) (PMMA) reactions are much more rapid in an ionic liquid than in a nonpolar solvents, and that a PMMA prepared in an ionic liquid has a molecular weight approximately five times higher than in benzene and toluene [21]. The ionic liquid monomer, DEMM-TFSI, also gives the ultra high molecular weight poly(DEMM-TFSI) by bulk polymerization with a conventional 2-2'-azoisobutyronitrile (AIBN) initiator [22]. However, control of the molecular weight was difficult due to the strong enhancement of the propagation rate coefficients $\left(k_{p}\right)$ in ILs. Although molecular weight control in the polymerization of polymerizable ILs is more successful using an atom transfer radical polymerization (ATRP) [20, 23, 24], there are few investigation of length control by other polymerization methods, such as conventional chain transfer radical (CTR) polymerization, adding chain transfer agents, or reversible addition fragmentation chain transfer (RAFT) polymerization. In this chapter, we describe the molecular weight-controlled polymerization of DEMM-TFSI by CTR polymerization and RAFT polymerization. We also detail the physicochemical properties of the resulting molecular weight-controlled ionic liquid polymer, poly(DEMM-TFSI), especially the thermal properties (glass transition temperature; $T_{g}$ ), ionic conductivity and the self-diffusion coefficient $(D)$ of poly-cation and anion in solution using pulsed-gradient spin echo NMR (PGSE-NMR) spectroscopy.

For electrochemical device applications, a good method to produce a flexible polymer electrolyte membrane with high conductivity and non-flammability is to use poly(ILs) as a host polymer for the gelation of ILs [22, 25]. Poly(ILs) have a higher affinity for ionic liquids than that of conventional polymers such as PMMA, poly(ethylene oxide) (PEO) and poly(vinylidenefluoride) (PVdF). In fact, the ionic liquid gel composite material including poly(ILs) showed higher ionic conductivity than that of the materials including conventional polymer such as a PMMA. A high degree of compatibility with the ionic liquid results in a high ionic conductivity and good physical properties even when only a small amount of polymer material is added. This allows the IL to be completely encapsulated, thereby avoiding liquid leakage accidents. Work in this area will be also described in this chapter.

\section{Preparation and physicochemical properties of DEMM-TFSI}

We developed a new type of polymerizable IL, $N, N$-diethyl- $N$ - (2-methoxyethyl)- $N$-methylammonium bis(trifluoromethylsulfonyl)imide (DEMM-TFSI in Fig. 1 ), with electrochemical stability in a wide range of potential. The preparation route of the DEMM-TFSI, was given elsewhere [22]. In brief, 2-(diethylamino)ethylmethacrylate was treated with 1.2 equiv. of methyliodide in tetrahydrofuran at $0{ }^{\circ} \mathrm{C}$ and stirred overnight, giving $\mathrm{N}, \mathrm{N}$-diethyl- $\mathrm{N}-(2-$ 
methacryloylethyl)- $N$-methylammonium iodide as a precipitate, which was filtered off and recrystallized in tetrahydrofuran-ethanol solvent. The recrystallized product was treated with exactly 1.0 equiv. of lithium bis(trifluoromethylsulfonyl)imide in deionized water for 5 h. After the reaction, the mixture was separated into two phases, the bottom phase being $\mathrm{N}, \mathrm{N}$-diethyl-N-(2-methacryloylethyl)- $N$ - methylammonium bis(trifluoromethylsulfonyl)imide.

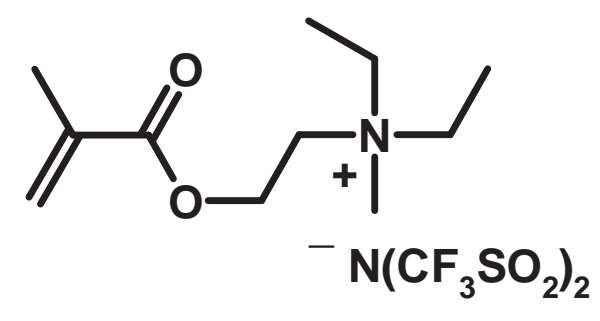

Figure 1. Molecular structure of DEMM-TFSI

The ionic conductivity is $0.6 \mathrm{mScm}-1$ at $25^{\circ} \mathrm{C}$ measured by a conductivity meter (HM-30R, DKK-TOA Corporation).

Fig.2 depicts the differential scanning calorimetry (DSC) and thermal gravimetric analysis (TGA) curves of the DEMM-TFSI. This polymerizable IL did not exhibit a clear melting or freezing temperature in a typical DSC measurement; however, the glass transition temperature $T_{\mathrm{g}}$ was observed at $-68{ }^{\circ} \mathrm{C}$. The decomposition temperature corresponding to a $10 \%$ weight loss according to TGA measurements occurred at $329^{\circ} \mathrm{C}$. DEMM-TFSI exists as an ionic liquid over a very wide temperature range, approximately $400{ }^{\circ} \mathrm{C}$.
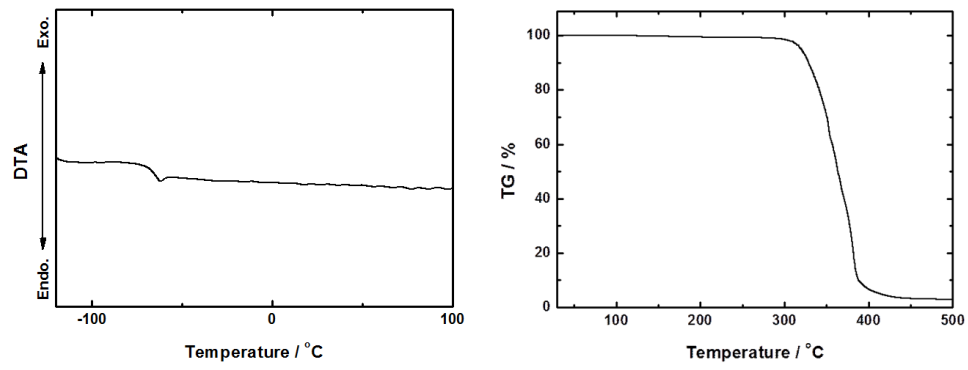

Figure 2. (a) Differential scanning calorimetry (DSC) and (b) thermal gravimetric analysis (TGA) results for the ionic liquid monomer, DEMM-TFSI at a heating rate of $5^{\circ} \mathrm{C} \mathrm{min}^{-1}$. 


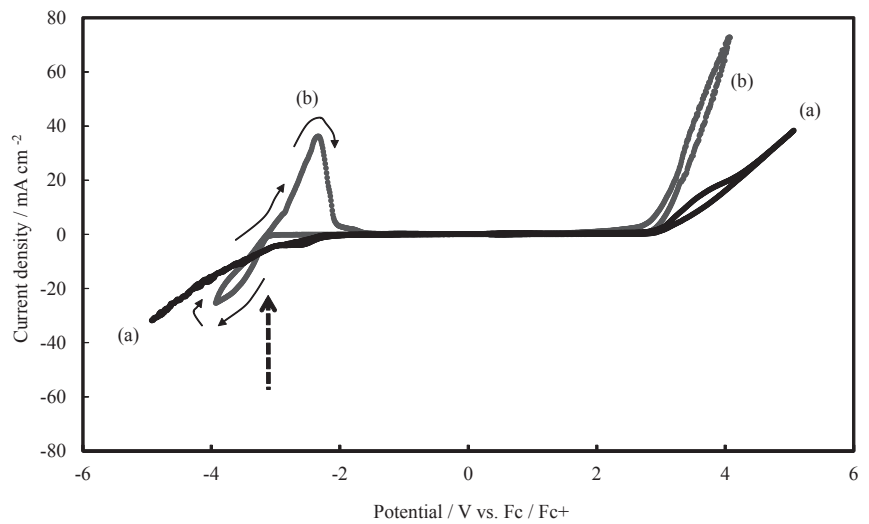

Figure 3. Cyclic voltammogram of an ionic liquid monomer, an organic electrolyte at $25^{\circ} \mathrm{C}$. Scan rate: $10 \mathrm{mVs}^{-1}$; platinum working and counter electrodes; $\mathrm{Ag} / \mathrm{Ag}^{+}$reference electrode. The potential value $(\mathrm{V})$ was referenced to the ferrocene $(\mathrm{Fc}) /$ ferrocenium $\left(\mathrm{FC}^{+}\right)$redox couple in each salt. (a) $0.1 \mathrm{~mol} \mathrm{~kg}^{-1}$ of DEMM-TFSI in propylene carbonate (PC) solution, (b) $0.1 \mathrm{~mol} \mathrm{~kg}^{-1}$ of LiTFSI in PC solution. The concentration is defined in terms of molality $=(\mathrm{mol}$ solute $/ \mathrm{kg}$ solvent). The dashed line arrow indicates the potential of the $\mathrm{Li} / \mathrm{Li}^{+}$couple.

Fig. 3 shows both the limiting reduction potentials $\left(E_{\text {red. }}\right)$ on platinum of the ionic liquid monomer as measured by cyclic voltammetry at room temperature, and a voltammogram of an ordinary organic electrolyte LiTFSI in PC. The sharp peaks around $-3.0 \mathrm{~V}$ are probably due to the deposition and dissolution of Li metal, since a color change of the working electrode by the metal deposition appears with a current loop at that potential. The $E_{\text {red. }}$ and the limiting oxidation potentials $\left(E_{\text {oxd. }}\right)$ were defined as the potential where the limiting current density reached $1 \mathrm{mAcm}^{-2}$. The $E_{\text {red. }}$ of the DEMM-TFSI ionic liquid monomer was positioned about $0.7 \mathrm{~V}$ positive against the $\mathrm{Li} / \mathrm{Li}^{+}$. We confidently expected this result, because the monomer molecule had an easily reduced double bond.

\section{Preparation of poly(DEMM-TFSI)}

\subsection{Radical polymerization of ionic liquid monomer; DEMM-TFSI}

The poly(IL), poly(DEMM-TFSI), was synthesized by the bulk polymerization method. First, the monomer was dissolved in acetonitrile, and the solution was treated with activated carbon; the resultant acetonitrile solution was evaporated and the purified monomer was dried in vacuum at $25{ }^{\circ} \mathrm{C}$. The ionic liquid monomer and 2,2'-Azoisobutyronitrile (AIBN), at a ratio of $1.0 \mathrm{~mol} \%$ to the amount of methacryl groups present in the monomer, were mixed until they became homogeneous. The mixture was degassed in vacuum at $50{ }^{\circ} \mathrm{C}$, and kept standing at $70{ }^{\circ} \mathrm{C}$ for $15 \mathrm{~h}$. After polymerization, the product polymer was dissolved in acetonitrile and precipitated into ethanol and water, before a final drying in vacuum at $70{ }^{\circ} \mathrm{C}$. The preparation scheme is shown in Fig. 4. 


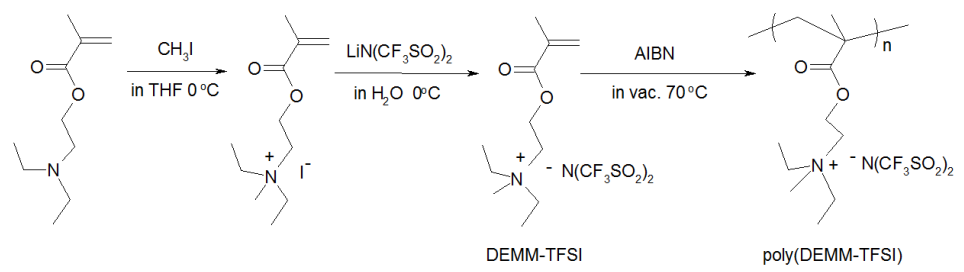

Figure 4. Synthesis of ionic liquid monomer (DEMM-TFSI) and poly(DEMM-TFSI).

It has been reported that poly(methyl methacrylate) (PMMA) reactions are much more rapid in an ionic liquid than in a nonpolar solvent such as benzene, and that a PMMA prepared in an ionic liquid has a molecular weight approximately five times higher than in benzene [21]. The ionic liquid monomer DEMM-TFSI also gives the ultra high molecular weight poly(DEMM-TFSI) by bulk polymerization with an AIBN initiator. Fig. 5 illustrates the GPC trace of the poly(DEMM-TFSI) product polymerized using a mol ratio of [monomer]/[AIBN] $=1: 0.01$. The resulting polymer was a rubbery solid, with a weight average molecular weight $\left(M_{w}\right)$ of $1,084,000$ and a polydispersity index by GPC analysis of 2.95 [PDI $=\left(M_{w}\right) /$ numberaverage molecular weight $\left.\left(M_{n}\right)\right]$.

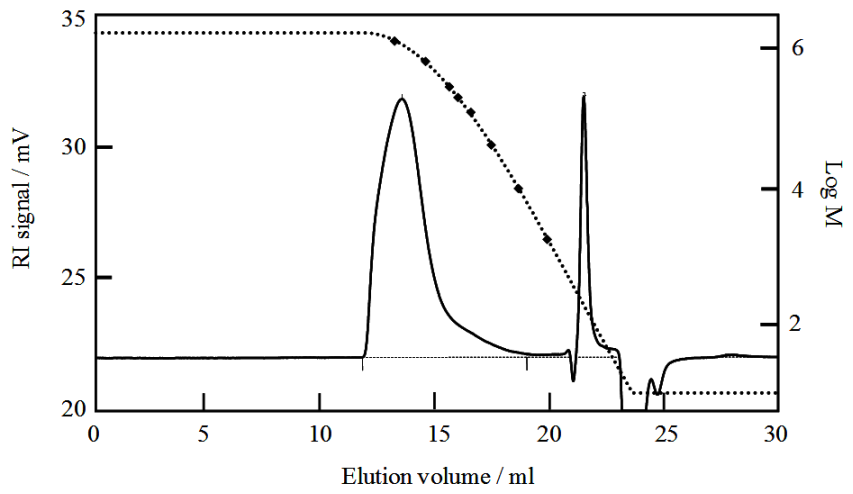

Figure 5. GPC trace of poly(DEMM-TFSI). $M_{n}=368,000 ; M_{w}=1,084,000 ; M_{w} / M_{n}=2.95$. GPC analyses were performed at $40{ }^{\circ} \mathrm{C}$, with a Shodex GPC-101 equipped with two, series-connected OHpak SB-806M HQ columns with a solution of $0.5 \mathrm{M}$ acetic acid and $0.2 \mathrm{M}$ sodium nitrate in acetonitrile and water $(1 / 1 \mathrm{v} / \mathrm{v})$ as the eluent. The weight- and numberaverage molecular weight were estimated on the basis of the calibration curve established with standard poly(ethylene oxide)s with the Shodex 480-II data station. 


\subsection{Molecular weight control of poly(DEMM-TFSI)}

It is well known when the radical polymerizations are conducted in an ionic liquid, a significant incerase of the $k_{p} / k_{t}$ ratio is normally observed in comparison to those carried out in other polar solvents $[18,26]$. Not only the rates of polymerization, but also the molecular weights of the polymers produced were considerably higher for several kinds of monomers. Also, the polymerizable ionic liquids, in our case DEMM-TFSI, give considerably higher molecular weight polymers in bulk radical polymerizations. The difficulty in molecular weight control might become disadvantageous in material development. In this section, we show how we succeeded in the molecular weight control of the radical polymerization process using DEMM-TFSI by simply adding a chain transfer reagent (CTA).

Fig. 6 illustrates the relationships between the number average molecular weights and the concentration of the charge transfer reagent, 3-mercapto-1-hexanol in bulk radical polymerization media using AIBN as a initiator at $50{ }^{\circ} \mathrm{C}$. We were able to synthesize poly (DEMMTFSI) over $M_{n}$ range from 5000 to 50,000, indicating that 3-mercapto-1-hexanol is an effective CTA under these conditions. The polydispersity index (PDI $\left.=M_{w} / M_{n}\right)$ was approximately 1.8 and 2.7 for polymer with a $M_{n}$ of ten thousand or less and several tens of thousands or more, respectively; these PDI values are not very different from those found with a conventional free radical polymerization.

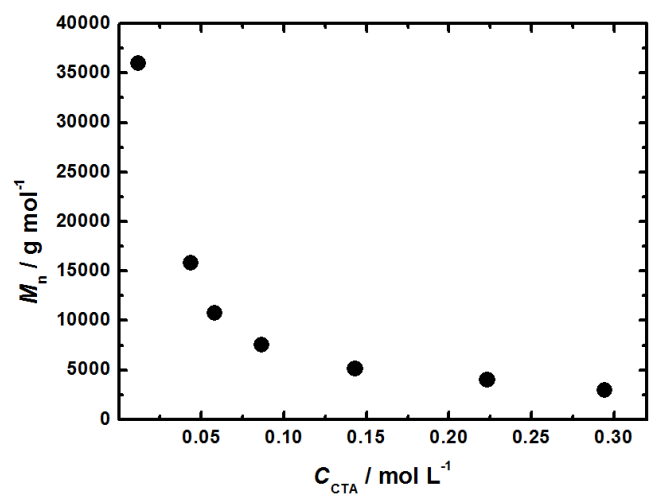

Figure 6. The relationship between the number average molecular weight of polymerized ionic liquid, DEMM-TFSI and the concentration of the charge transfer reagent 3-mercapto-1-hexanol, using 2,2'-azobis(isobutyronitrile) (AIBN) as initiator at $50{ }^{\circ} \mathrm{C}$. Molar ratio: [DEMM-TFSI] / [AIBN] = $1 /$ 0.015. Number-average molecular weights were as determined by GPC.

Using the controlled/living radical polymerization techniques that have shown remarkable progress recently is perhaps the best choice for preparation of the poly(ILs) with controlled molecular weight and a narrow PDI. Two such possibilities are atom transfer radical polymerization (ATRP) and reversible addition-fragmentation chain transfer (RAFT) polymerization [27]. We have already achieved exceptionally dense grafting of well-defined pol(DEMM-TFSI) on a solid surface, known as a concentrated polymer brush prepared by surface initiated ATRP. Such a polymer brush surface showed unique properties, including 
high modulus, super lubrication, and unique size exclusion that were quite different and even unpredictable from those of the previously studied semidilute polymer brushes [24]. The polymerization of DEMM-TFSI was well controlled and exhibited living characteristics when a $\mathrm{Cu}(\mathrm{I}) \mathrm{Cl}$ and $\mathrm{Cu}(\mathrm{II}) \mathrm{Cl}_{2}$ mixture and 2,2'-bipyridine complex was used as the catalyst system and ethyl-2-bromoisobutyrate as initiator. However, if such synthesized poly(ILs) are used for the electrochemical devices, some residue of the metallic catalyst may ruin the reliability of the devices. An apparent disadvantage of applying ATRP for the synthesis of poly(ILs) is the unavoidable complexation of polymers with the catalytic copper ions. However, RAFT polymerization is free of this problem, as no metal source is involved.

Compared to ATRP, there are not many examples of research into RAFT polymerization. Because papers concerning the RAFT polymerization of polymerizable quaternary ammonium type ionic liquids are very few in number, we investigated the kinetics of the RAFT polymerization of DEMM-TFSI. Figure 7 (a) shows the variation in $\ln \left([\mathrm{M}]_{0} /[\mathrm{M}]_{\mathrm{t}}\right)$ versus polymerization time for the polymerization of DEMM-TFSI in acetonitrile at $50{ }^{\circ} \mathrm{C}$ with AIBN in the presence of 2-cyano-2-propyl benzodithioate (CPBT). The reaction was conducted at a ratio of $[\text { DEMM-TFSI }]_{0} /[\text { CPBT }]_{0}=200 / 1$, the concentration of DEMM-TFSI and AIBN being $75 \mathrm{wt} . \%$ and $0.5 \mathrm{wt} . \%$ in acetonitrile, respectively. Almost full conversion was reached after 5 hours and an almost linear first-order kinetic plot is seen until almost $100 \%$ conversion. Nevertheless, a linear increase in the number-average molecular weight determined by GPC spectroscopy with conversion is observed, indicating a constant number of propagating chains throughout the polymerization (Figure $7(b)$ ). The PDI value is consistently small $\left(M_{w} / M_{n}=1.45-1.24\right)$ from the first stage of the polymerization to the end. This is an indication that the polymer chain end is capped with the fragments of CPBT, as expected according to the general mechanism of the RAFT process. These data indicated the molecular weight controlled synthesis of poly(DEMM-TFSI) with a narrow PDI can be successfully performed by RAFT polymerization of DEMM-TFSI.
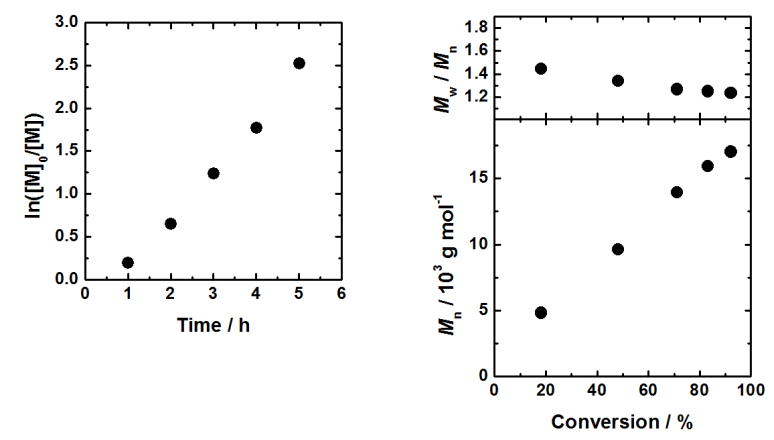

Figure 7. (a) Plot of $\ln \left([\mathrm{M}]_{0} /[\mathrm{M}]_{t}\right)$ versus time and (b) evolution of number average molecular weight $\left(M_{n}\right)$ and polydispersity index $\left(M_{w} / M_{n}\right)$ for the RAFT polymerization of DEMM-TFSI with 2,2'-azobis(isobutyronitrile) (AIBN) in the presence of 2-cyano-2-propyl benzodithioate (CPBT) in acetonitrile at $50{ }^{\circ} \mathrm{C}:$ [DEMM-TFSI $]_{0} /[\mathrm{CPBT}]_{0} /[\mathrm{AIBN}]_{0}=200 / 1 /$ 3.91. The number average molecular weights and conversion were determined by GPC and ${ }^{1} \mathrm{H}-\mathrm{NMR}$. 


\section{Physicochemical properties of poly(DEMM-TFSI)}

In Fig. 8 are shown the $T_{g}$ values of poly(DEMM-TFSI) with various $M_{n}$ values and relatively small polydispersity index values $\left(M_{w} / M_{n}<1.2\right)$ measured by differential scanning calorimetry (DSC) analysis during heating at $10 \mathrm{deg} / \mathrm{min}$. versus the number average molecular weight $\left(M_{n}\right)$. The polymer was prepared by atom transfer radical polymerization (ATRP) using a complex catalyst consisting of copper chloride and 2,2'-bipyridine in acetonitrile [24]. ATRP represents one of the branches of living radical polymerization (LRP). The $M_{n}$ value was estimated as an absolute value, assuming a 100\% initiation, from the monomer-to-initiator molar ratio and the conversion determined by ${ }^{1} \mathrm{H}-\mathrm{NMR}$ using a JEOL JEM-ECX400 spectrometer. The $M_{w} / M_{n}$ value was determined by poly(ethyleneglycol)-calibrated gel permeation chromatography (GPC) using a Shodex GPC-101 high-speed liquid chromatography system.

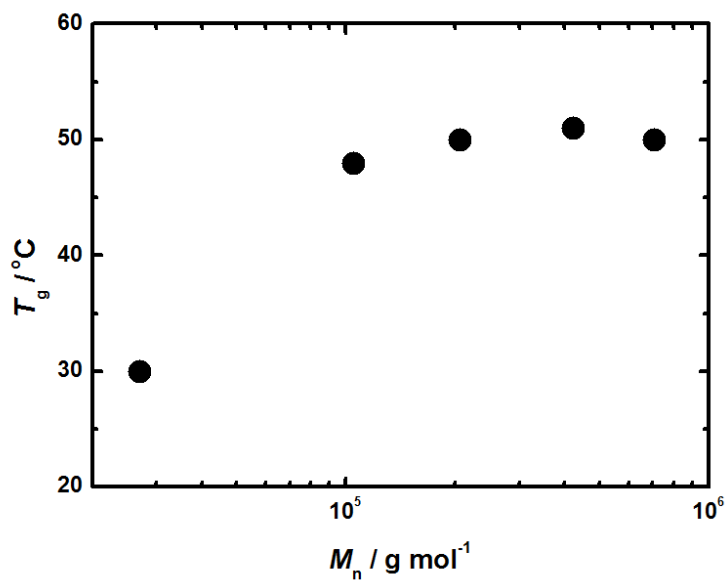

Figure 8. Glass transition temperatures, measured calorimetrically during heating at $10 \mathrm{deg}$. / min, versus number average molecular weight.

The glass transition temperature is related to the start of the segmental motion of polymers. In general, polymers with more free volume have a lower $T_{g}$ value and that temperature is essentially independent of molecular weight because the free volume ratio per segment of polymer materials is the same even if the length of a polymer main chain changes. However, it is known that a lower molecular weight polymer usually has lower $T_{\mathrm{g}}$ value. Because the chain ends have high mobility and more free volume than the middle part of polymer, the free volume increases with the numbers of terminals, and $T_{g}$ decreases as a result.

A poly-cation type material such as poly(DEMM-TFSI) has bulky tetra-alkyl ammonium functional groups in each unit and has a relatively low $T_{g}$ value due to its large free volume due to the effect of the electrostatic repulsions of cationic groups. A polymer with a molecu- 
lar weight that exceeds 100,000 has roughly a $T_{g}$ of $50{ }^{\circ} \mathrm{C}$ while, on the other hand, a 20 degrees lower value of $T_{g}$ of $30{ }^{\circ} \mathrm{C}$ was found for a polymer with a $M_{n}$ about 10,000, presumably due to the chain ends effect. The relationships between $M_{n}$ and $T_{g}$ of this poly(IL) had a similar trend to that of polystyrene $[28,29]$. We realized that the $T_{g}$ rose greatly on polymerization only up to about 50 of degree of polymerization, though the $T_{g}$ of the monomer had shown an extremely low value of $-68^{\circ} \mathrm{C}$.

It was thought that a excellent solid polymer electrolyte with high physical strength and high ionic conductivity could be developed by the polymerization of ionic liquid monomers, so much attention has been directed toward developing poly(ILs) in order to avoid some disadvantages of liquid electrolytes, such as leakage and flammability, in energy device applications, including the lithium ion rechargeable battery, the electric double layer capacitor and dye-sensitized solar cell. However, the ionic conductivity of the polymerized ionic liquids was generally considerably lowered due to both the considerable elevation of the glass transition temperature and a reduced number of mobile ions, as one of ions is fixed to the polymer chain and so cannot move.

Fig. 9 shows the temperature dependence of the ionic conductivity for a series of poly(DEMM-TFSI)s with different $M_{n}$ values. In the case of our polymer, the ionic conductivity of poly(DEMM-TFSI) was four digits or more lower than that of an ionic liquid such as DEME-TFSI (molecular structure is indicated in Fig. 11.) in the room temperature region. Unfortunately, this level of conductivity is not practicable for devices. However, an interesting point is that neither the value of the ionic conductivity nor the temperature dependency of the conductivity do not depend on the molecular weight of the polymer, and exhibit an almost constant value. Thus, polymers with $M_{n}$ of 27,000, 250,000 and 710,000 have $T_{g}$ values of 40,50 and $50{ }^{\circ} \mathrm{C}$, respectively. The ionic conductivity of these polymers continuously changes without an inflection point in the area before and after the $T_{g}$. There seems to be no correlation between the ionic conductivity value and the glass transition temperature. It is widely accepted that ion conduction in an amorphous polymer matrix should occur above the glass transition temperature as it is coupled with a segmental motion of polymer chain [30]. The matrix polymer solvated the mobile ions and created a liquid-like environment around the ions. However, in the poly(DEMM-TFSI) matrix, it seems the anion moves independently of the polymer chain which stops its segmental motion below the glass transition temperature. The mobility of the anion in this poly(IL) seems to be different from that of the solvated ions in the polymer without any dissociable ionic substituent, such as polyethylene oxide (PEO) that contains a lithium salt. Ionic conduction does not appear in a PEO matrix below the glass transition temperature. In the poly(DEMM-TFSI), an alternative anion conduction mechanism that does not involve polymer motion might exist. There are only a few previous studies related to the ionic conduction mechanism in poly-cation and poly-anion systems below $T_{g}$. We are planning to combine DSC and ionic conductivity measurements using a dielectric relaxation spectroscopy measurement in order to improve our understanding of this interesting phenomenon. 


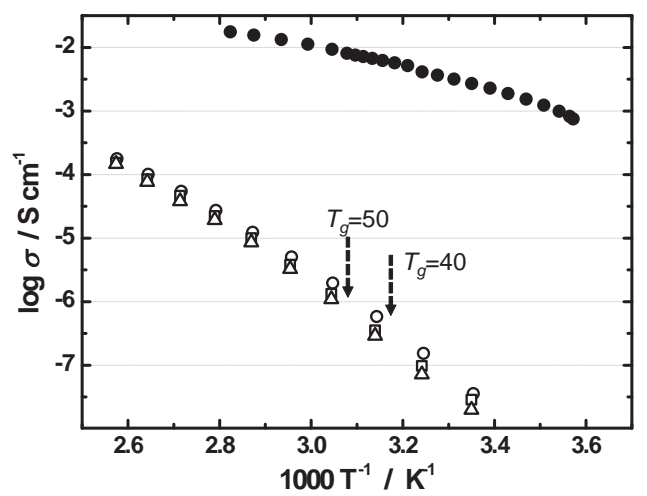

Figure 9. Temperature dependence of the ionic conductivity for poly(DEMM-TFSI)s with different $M_{n}$ values and an ionic liquid by the complex impedance method [24]. Open circle, Poly(DEMM-TFSI) with $M_{n}=27,000$; open triangle, $M_{n}=250,000$; open square, $M_{n}=710,000$; filled circle, ionic liquid (DEME-TFSI). Ionic conductivity measurements were made by an AC-impedance method using a multi-frequency LCR meter (Agilent Technology E4980A Precision LCR). The sample was loaded at $100{ }^{\circ} \mathrm{C}$ between two polished stainless-steel discs acting as ion-blocking electrodes with ceramic-sheet spacer with a $100 \mu \mathrm{m}$ thickness. The measurement cell was set in a thermostat oven chamber and collected at various frequencies ranging from $20 \mathrm{~Hz}$ to $2 \mathrm{MHz}$ and various temperatures ranging from -5 to $125^{\circ} \mathrm{C}$. The conductivity of the ionic liquid was measured at various temperatures by a conductivity meter (HM-30R, DKK-TOA Corporation).

Hayamizu et al. have succeeded in measuring the self diffusion coefficients $(D)$ values of the solvent molecule, the cation, the anion, and the polymer molecule in a PEO-type gel electrolyte system by the method of pulsed gradient spin-echo multinuclear NMR (PGSE-NMR) $[31,32,33]$. We also carried out PGSE-NMR measurements in order to evaluate the $D$ value of the poly-cation and counter anion (TFSI) in a relatively high viscosity poly(DEMM-TFSI) solution in acetonitrile. The polymer concentration of the solution used for the measurement is 20 percent by weight, a value that far exceeded the overlap concentration, $C^{*}$, where the polycation chains can contact and entangle with each other. So, the movement of the polymer chain was suppressed in this concentration region, hence it can be said that the environment was in a gel-like state.

Fig. 10 represents the NMR echo signal attenuation of a poly(DEMM-TFSI) solution in acetonitrile at $25{ }^{\circ} \mathrm{C}$ probed by ${ }^{1} \mathrm{H}$ and ${ }^{19} \mathrm{~F}$ nuclear signals attributed to the methyl proton on the ammonium cation and acetonitrile and the TFSI anion. The attenuation due to free diffusion in the Stejskal and Tanner sequence using half-sine-shaped gradient pulses is given by

$$
E=S / S_{0}=\exp \left(-\gamma^{2} g^{2} \delta^{2} D(4 \Delta-\delta) / \pi^{2}\right)
$$

where $\gamma$ is the gyromagnetic ratio, $S$ is the amplitude of the echo signal and $S_{0}$ is the amplitude where $g=0, g$ is the amplitude of the gradient pulse, $\delta$ is the duration of the gradient 
pulse, and $\Delta$ is the interval between the gradient pulses. Thus, $D$ could be determined from the slope of a plot of $\ln E$ against varying $g$. In the present experiments, the maximum $g$ value was $13.5 \mathrm{~T} / \mathrm{m}$, the $\Delta$ was set to $10 \mathrm{~ms}$, and the $\delta$ values varied in the range of 0.1 to 3 ms. The self-diffusion coefficient $D$ of the poly-cation, anion, and solvent molecules are $1.6 \times$ $10^{-11}, 4.5 \times 10^{-10}$ and $2.8 \times 10^{-9} \mathrm{~m}^{2} / \mathrm{s}$, respectively. The $D$ value of the anion molecule was about $1 / 6$ of that of the solvent molecule. However, one might think that the anion has the same degree of mobility as the solvent molecule because it has a several times larger molecular volume than the solvent molecule. That is to say, the anion can move like a solvent molecule in a very high concentration solution of poly-cation without suffering a strong restraint due to electrostatic effects. The anion seems to be able to escape from the restraint of the polycation even in a very high concentration poly-cation solution.

(a)

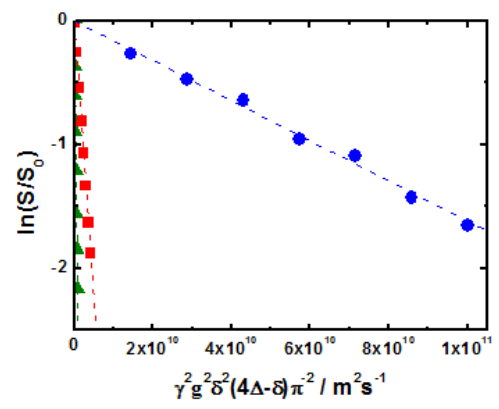

(b)

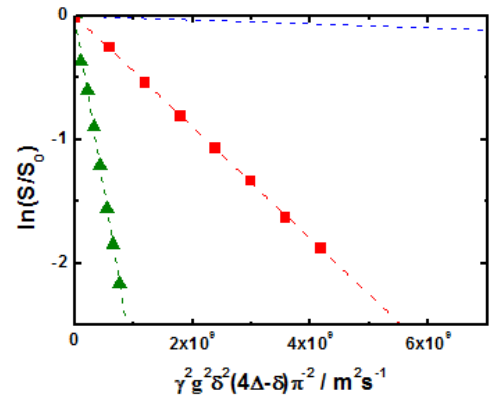

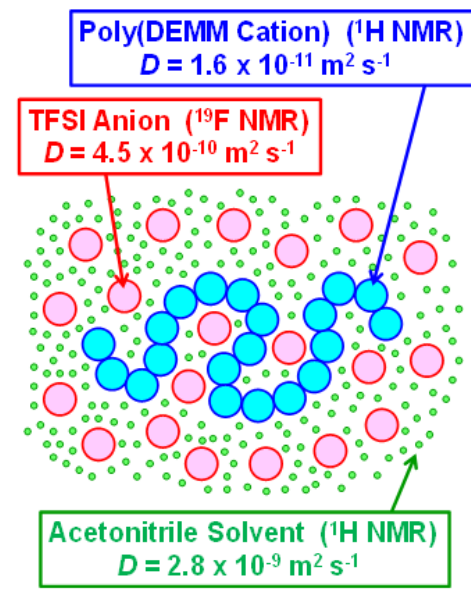

Figure 10. (a) PGSE attenuation plots for the single $\mathrm{N}-\mathrm{CH}_{3}$ of [Poly(DEMM-TFSI)] and the $\mathrm{CH}_{3}$ signal of acetonitrile probed by the ${ }^{1} \mathrm{H}$ nucleus and the TFSI anion probed by ${ }^{19} \mathrm{~F}$ at $25^{\circ} \mathrm{C}$ obtained by varying $\delta$ at different $\mathrm{g}$ values for $\Delta=10$ ms. (b) Maginified plots area. (c) Self-diffusion coefficient values in high concentration poly(DEMM-TFSI) in acetonitorile solution. 


\section{High rate performance of a lithium polymer battery using an ionic liquid polymer composite}

Some investigators have attempted to develop a non-flammable polymer electrolyte system; we have developed a polymer-gel electrolyte system consisting of a lithium salt in an ionic liquid and poly(ILs), which we have called a LILP composite system (Li-salt + ionic liquids + poly(ILs)). Generally, a binary Li-IL, specifically, a lithium salt dissolved in an ionic liquid having the same anion are used for LILP system. Several LILP systems with conductivities over $10^{-3} \mathrm{~S} \mathrm{~cm}^{-1}$ at room temperature have been developed [34, 25, 17]. However, since the binary Li-IL have a considerably high viscosity, the cell containing such liquids has a poor charge / discharge performance at a relatively large current, namely a lower power density, compared to conventional cells using the flammable organic solvent. And, there have been few reports of the performance of Li ion cells incorporating a LILP system. We are aiming to develop a truly safe $\mathrm{Li}$ ion polymer cell with a good charge and discharge performance at a large current, we discovered that the choices of $\mathrm{LiMn}_{2} \mathrm{O}_{4}$ and $\mathrm{Li}_{4} \mathrm{Ti}_{5} \mathrm{O}_{12}$ [36] as, respectively, the cathode and anode active material, produced a faster charge / discharge reaction than conventional $\mathrm{LiCoO}_{2}$ and graphite systems, and we combined these active materials and poly(DEMM-TFSI), which is very compatible with ionic liquids, as a novel LILP system. Our novel $\mathrm{Li}$ polymer cell has the following structure: negative electrode: $\mathrm{Li}_{4} \mathrm{Ti}_{5} \mathrm{O}_{12} /$ LILP-including ultrahigh molecular weight ionic liquid polymer / positive electrode: $\mathrm{LiMn}_{2} \mathrm{O}_{4}$. In this section, we will discuss the performance of this cell.

Poly (DEMM-TFSI) has the capability to dissolve a lithium salt independent of the presence of a liquid electrolyte. In a polarizing microscope analysis of Poly(DEMM-TFSI) which contained $1 \mathrm{M}$ concentration of dissolved lithium salt $\mathrm{LiClO}_{4}$, we did not observe the birefringence indicating the existence of crystals. Thus, there must have been a complete dissociation of the lithium salt in the polymer matrix as the polymer itself has a non-crystalline nature. DSC measurements indicate that prepared poly(DEMM-TFSI) has a glass transition temperature $\left(T_{\mathrm{g}}\right)$ of approximately $50{ }^{\circ} \mathrm{C}$. Thus, a poly(DEMM-TFSI) / lithium salt composite could potentially serve as an all-polymer electrolyte at temperatures over $50{ }^{\circ} \mathrm{C}$.

Moreover, poly(DEMM-TFSI) dissolves in a variety of quaternary ammonium ionic liquids to make a gel. For example, the ionic liquid, $N, N$-diethyl- $N$-(2-methoxyethyl)- $N$-methylammonium bis(trifluoro- methylsulfonyl) imide (DEME-TFSI, molecular structure is indicated in Fig. 11.) containing only $5 \%$ of the ultrahigh molecular weight poly(DEMM-TFSI) lost its liquid characteristics and became a gel. It seems that the strong cohesiveness and loss of liquidity appear because of the entanglement effect of long polymer chains. When we adjusted the solution to a suitable viscosity by adding a supplementary solvent, in our case a propylene carbonate (PC) and vinylene carbonate (VC) mixture, it filled the pore space in the electrode and the separator.

The ionic liquid/poly(ILs) composite from which the solvent is removed by vacuum evaporation at a relatively high temperature has no components that leak out of the electrode. However, the high-polarity LILP matrix interacted with the supplementary solvent (PC + VC) and probably obstructed perfect evaporation of added solvents. The weight percentage 
of remained solvent in the composite was $1.7 \mathrm{wt} \%$. We reported that the vinylene carbonate $(10 \mathrm{wt} \%)$ in the electrolyte Li-DEME-TFSI, composed of an ionic liquid, DEME-TFSI and LiTFSI was effective as solid electrolyte interface (SEI) forming additives on the carbon materials such as graphite used as an active material in the anode of a lithium ion cell [9]. Holzapfel and co-workers reported that $2 \%$ VC to ionic liquid, EMI-TFSI, contributed to the SEI formation, although the effect was not perfect [37]. Also in this case, there will be a possibility that the remained VC in composite contributes to the SEI formation. However, we realized that the effective SEI to prevent capacitance deterioration with charge/discharge cycles was not formed by the too small amounts (1.7 wt\%) of carbonate solvents in LILP composite from the cycling behavior of the cell. A highly reliable polymer battery is not easily obtained when the polymerization is carried out in the battery bag. In such an "in-situ radical polymerization", some initiator and unreacted monomer may remain in the polymer matrix. However, our process makes possible the preparation of an electrolyte with few impurities through the use of the purified polymer combined with the binary Li-IL.
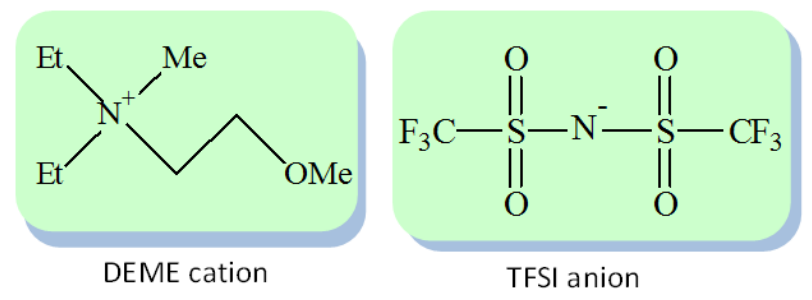

Figure 11. Molecular structure of ionic liquid, DEME-TFSI

Fig. 12 shows both the limiting reduction $\left(E_{\text {red. }}\right)$ and oxidation $\left(E_{\text {oxd. }}\right)$ potentials of the poly(DEMM-TFSI) in PC as measured by cyclic voltammetry at room temperature. The $E_{\text {red }}$. of the poly(DEMM-TFSI) can definitely be seen at around $2.0-2.5 \mathrm{~V}$ positive relative to $\mathrm{Li} / \mathrm{Li}$ + . However, its presence is not clear, and the current density is small because, we carried out the measurement in rather dilute conditions to avoid turbulence caused by an increased viscosity in the more concentrated polymer solution. In addition, the $E_{\text {red. }}$ of the DEME based ionic liquids was merely somewhat positive against the $\mathrm{Li} / \mathrm{Li}+$ [9]. Thus, we realized the need either to select an electrode that would avoid cathodic decomposition during the charge-discharge cycling, or to form a more effective protective layer, such as a solid electrolyte interface (SEI), on the negative electrode material.

We selected high power active electrode materials, and combined them with a LILP system and prepared two type vapor-free lithium ion polymer cells for demonstration purposes. The negative $\mathrm{Li}_{4} \mathrm{Ti}_{5} \mathrm{O}_{12}$ electrodes (AKO-6), had a charge capacity of $0.42 \mathrm{mAh} \mathrm{cm}{ }^{-2}$, an area density of $3.00 \mathrm{mg} \mathrm{cm}^{-2}$, and had an active electrode layer 25 micron-m thick on a copper foil. The other negative electrode used was a hard carbon electrode (AKT-2) with a charge 
capacity of $1.29 \mathrm{mAh} \mathrm{cm}^{-2}$, an area density of $2.96 \mathrm{mg} \mathrm{cm}^{-2}$, and a 33 micron-m in thick electrode active layer on a copper foil. The first positive electrode, a $\mathrm{LiMn}_{2} \mathrm{O}_{4}$ electrode (CKT-22) that was paired with the AKO-6 negative electrode, had a charge capacity of $0.49 \mathrm{mAh} \mathrm{cm}{ }^{-2}$, an area density of $6.60 \mathrm{mg} \mathrm{cm}^{-2}$ and an electrode active layer $36-37$ micron-m in thickness on an aluminum foil. The second $\mathrm{LiMn}_{2} \mathrm{O}_{4}$ electrode (CKT-9), paired with the AKT-2 had a

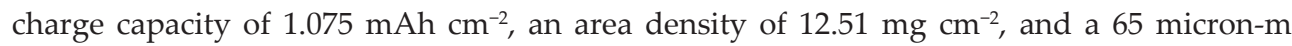
thick electrode active layer on an aluminum foil. The specification of the electrodes are summarized in Table 1. The details of the preparation method have been described in our previous paper [9].

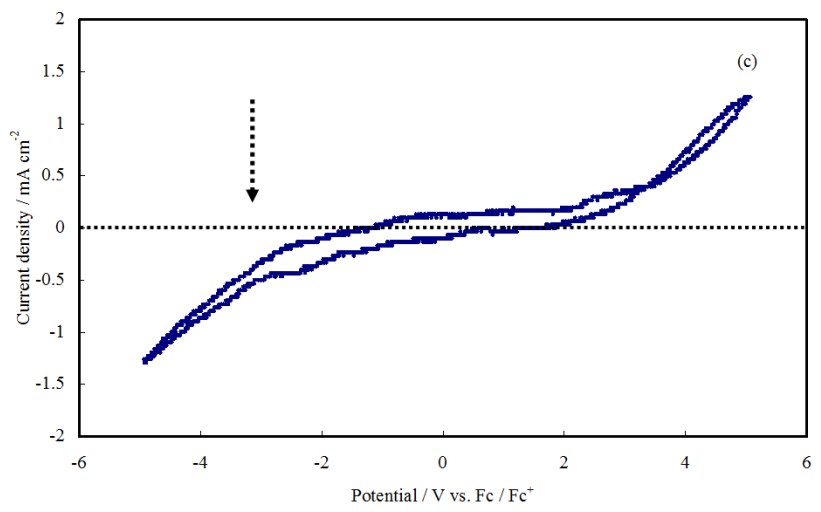

Figure 12. Cyclic voltammogram of poly(DEMM-TFSI) in $P C$ at $25^{\circ} \mathrm{C}$. Scan rate: $10 \mathrm{mVs}^{-1}$; platinum working and counter electrodes; $\mathrm{Ag} / \mathrm{Ag}^{+}$reference electrode. The potential value $(\mathrm{V})$ was referenced to the ferrocene $(\mathrm{Fc}) / \mathrm{ferrocenium}$ $\left(\mathrm{FC}^{+}\right)$redox couple in each salt. Polymer concentration, $0.002 \mathrm{~mol} \mathrm{~kg}^{-1}$ poly(DEMMTFSI) in PC solution. The concentration is defined in terms of molality $=$ (mol solute $/ \mathrm{kg}$ solvent). The dashed line arrow indicates the potential of the $\mathrm{Li} / \mathrm{Li}^{+}$ couple.

\begin{tabular}{ccccccc}
\hline Code & Active material Polarity & $\begin{array}{c}\text { Charge capacity } \\
\left(\mathrm{mAh} \mathrm{cm}{ }^{-2}\right)\end{array}$ & $\begin{array}{c}\text { Area density } \\
\left(\mathrm{mg} \mathrm{cm}^{-2}\right)\end{array}$ & $\begin{array}{c}\text { Active layer } \\
\text { thickness }(\mu \mathrm{m})\end{array}$ & $\begin{array}{c}\text { Current } \\
\text { collector } /(\mu \mathrm{m})\end{array}$ \\
\hline AKO-6 & $\mathrm{Li}^{4} \mathrm{Ti}^{5} \mathrm{O} 12$ & Negative & 0.42 & 3.00 & 25 & $\begin{array}{c}\text { Copper/13 } \\
\text { CKT-22 }\end{array}$ \\
$\mathrm{LiMn}_{2} \mathrm{O} 4$ & Positive & 0.49 & 6.60 & $36-37$ & Aluminium/20 \\
\hline AKT-2 & Hard carbon & Negative & 1.29 & 2.96 & 33 & Copper/13 \\
CKT-9 & LiMn $_{2} \mathrm{O}^{4}$ & Positive & 1.075 & 12.51 & 65 & Aluminium/20 \\
\hline
\end{tabular}

Table 1. Electrode specification.

In Fig. 13, we show the first and second charge-discharge potential curves at $40{ }^{\circ} \mathrm{C}$ of the demonstration cells, consisting of hard carbon/LILP (1.3 mol of LiTFSI dissolved in poly(DEMM-TFSI)/ DEME-TFSI composite, giving a polymer concentration of $5.4 \mathrm{wt} \%$ )/ 
$\mathrm{LiMn}_{2} \mathrm{O}_{4}$. About $26 \%$ of the charge capacity was lost in the first cycle; however, from that point on, the cell exhibited an efficiency of $96 \%$ or more.

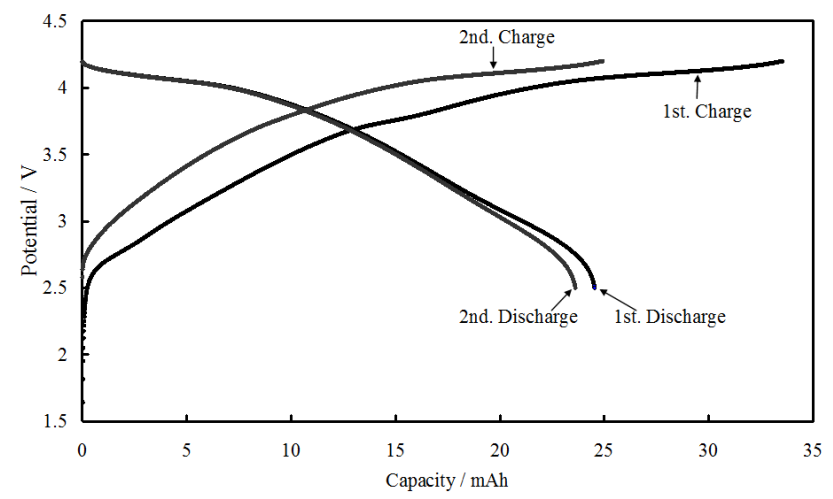

Figure 13. First and second charge/discharge curves of lithium polymer cell at $0.05 \mathrm{C}$ current at $40{ }^{\circ} \mathrm{C}$. Positive electrode $=\mathrm{LiMn}_{2} \mathrm{O}_{4}$; negative electrode $=$ hard carbon; electrolyte $=1.30 \mathrm{~mol} \mathrm{~kg}^{-1}$ of LiTFSI in a DEME-TFSI and poly(DEMM-TFSI) composite. The concentration is defined in terms of molality $=$ (mol solute/kg polymer-ionic liquid composite). The polymer concentration for the composite electrolyte was $5.4 \mathrm{wt} \%$.

The rate capability of this cell at $40{ }^{\circ} \mathrm{C}$ appears in Fig. 14. As the discharge current increased, the discharge capacity of this cell decreased significantly faster than that of a cell using conventional materials. The capacity at $1 \mathrm{C}$ discharge was approximately $63 \%$ of that at $0.1 \mathrm{C}$ discharge. Most likely, the greater decrease at large discharge currents in the capacity of the cell using the LILP electrolyte resulted from a large internal resistance in the cell. The cycling behavior of this cell, plotted in Fig. 15, was not suitable for practical use. When we set the upper limit voltage at $4.2 \mathrm{~V}$, the cell deteriorated sooner than with a voltage of $4.0 \mathrm{~V}$. The CV measurements suggested that degradation of the polymer or ionic liquid was occurring during the charge-discharge cycles. It is necessary to establish a method of forming an effective SEI if a practicable cycle performance is to be achieved.

We then prepared another type of lithium polymer cell, comprising $\mathrm{Li}_{4} \mathrm{Ti}_{5} \mathrm{O}_{12} /$ LILP (1.3 mol of LiTFSI dissolved in poly(DEMM-TFSI) / DEME-TFSI composite, $5.4 \mathrm{wt} \%$ polymer concentration) / $\mathrm{LiMn}_{2} \mathrm{O}_{4}$. Because the intercalation-deintercalation potential of $\mathrm{Li}_{4} \mathrm{Ti}_{5} \mathrm{O}_{12}$ is around $1.5 \mathrm{~V}$ vs. $\mathrm{Li} / \mathrm{Li}^{+}$potential, our prepared cell had about $3.0 \mathrm{~V}$ of charging potential with $\mathrm{LiMn}_{2} \mathrm{O}_{4}$. The overall cell reactions can be described as follows:

negative electrode,

$$
\mathrm{Li}\left[\mathrm{Li}_{1 / 3} \mathrm{Ti}_{5 / 3}\right] \mathrm{O}_{4}+x \mathrm{Li}^{+}+x e^{-} \Leftrightarrow \mathrm{Li}_{1+x}\left[\mathrm{Li}_{1 / 3} \mathrm{Ti}_{5 / 3}\right] \mathrm{O}_{4}
$$

positive electrode, 


$$
\mathrm{LiMn}_{2} \mathrm{O}_{4} \Leftrightarrow \mathrm{Li}_{1-x} \mathrm{Mn}_{2} \mathrm{O}_{4}+x \mathrm{Li}+x e^{-}
$$

overall reaction,

$$
\mathrm{Li}\left[\mathrm{Li}_{1 / 3} \mathrm{Ti}_{5 / 3}\right] \mathrm{O}_{4}+\mathrm{LiMn}_{2} \mathrm{O}_{4} \Leftrightarrow \mathrm{Li}_{1+x}\left[\mathrm{Li}_{1 / 3} \mathrm{Ti}_{5 / 3}\right] \mathrm{O}_{4}+\mathrm{Li}_{1-x} \mathrm{Mn}_{2} \mathrm{O}_{4}
$$

The theoretical capacity of $\mathrm{Li}_{4} \mathrm{Ti}_{5} \mathrm{O}_{12}$ was expected to be approximately $175 \mathrm{mAh} \mathrm{g}^{-1}$. In our electrode, the discharge capacity was $171 \mathrm{mAh} \mathrm{g}^{-1}$. The performances of the prepared cell are shown in Figs. 16-18.

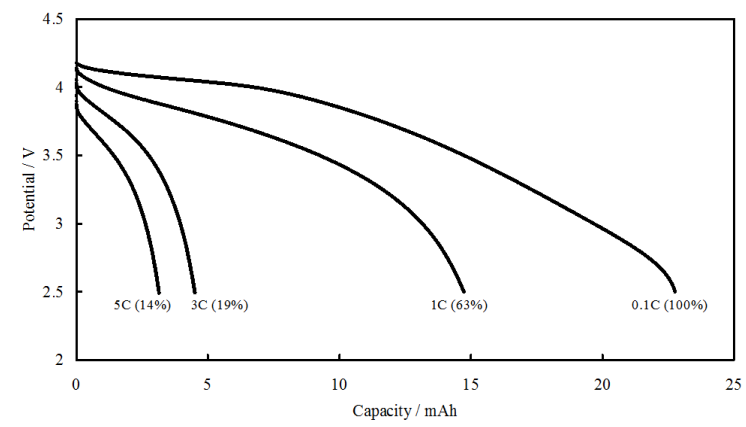

Figure 14. Discharge curves of the lithium polymer cell at various current densities at $40{ }^{\circ} \mathrm{C}$. The positive electrode $=$ $\mathrm{LiMn}_{2} \mathrm{O}_{4}$; negative electrode $=$ hard carbon; electrolyte $=1.30 \mathrm{~mol} \mathrm{~kg}^{-1}$ of LiTFSI in DEME-TFSI and poly(DEMM-TFSI) composite. The concentration is defined in terms of molality $=$ (mol solute $/ \mathrm{kg}$ polymer-ionic liquid composite). The polymer concentration for the composite electrolyte was $5.4 \mathrm{wt} \%$.

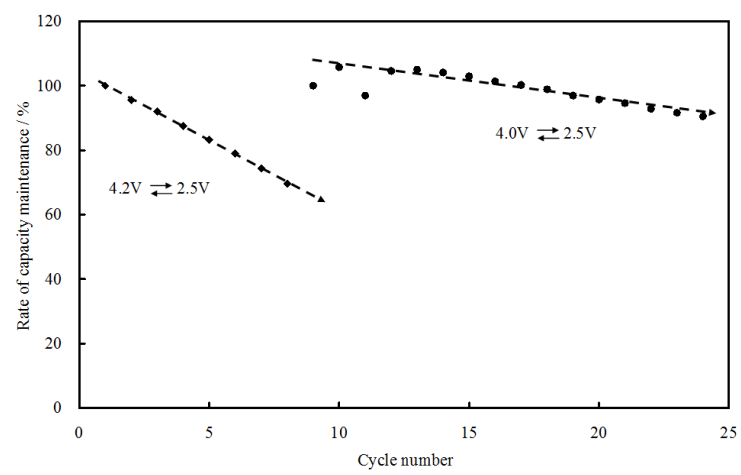

Figure 15. Cycle life of lithium polymer cell including hard carbon as negative active material. The charge-discharge process was performed at $0.1 \mathrm{C}$ at $40{ }^{\circ} \mathrm{C}$. The cut-off voltages were $4.2 \mathrm{~V}$ and $2.5 \mathrm{~V}$ for nine cycles, and $4.0 \mathrm{~V}$ and $2.5 \mathrm{~V}$ from 10 th to 24 th cycle. 


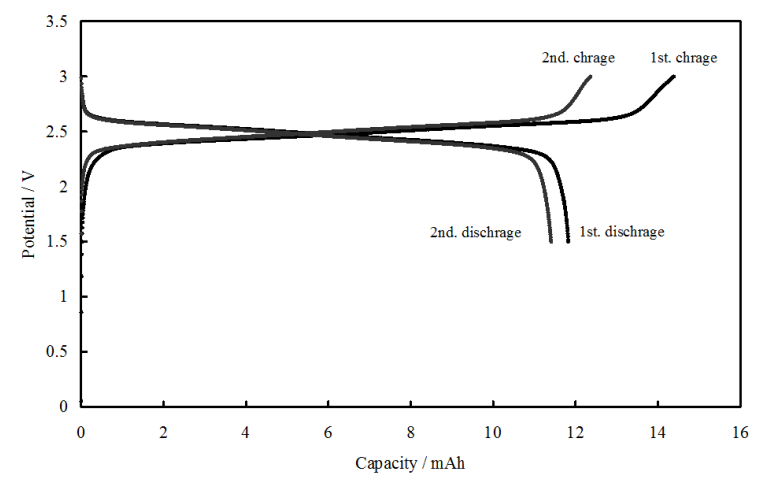

Figure 16. First and second charge/discharge curves of lithium polymer cell at $0.05 \mathrm{C}$ current at $40{ }^{\circ} \mathrm{C}$. The positive electrode $=\mathrm{LiMn}_{2} \mathrm{O}_{4}$; negative electrode $=\mathrm{Li}_{4} \mathrm{Ti}_{5} \mathrm{O}_{12}$; electrolyte $=1.30 \mathrm{~mol} \mathrm{~kg}{ }^{-1}$ of LiTFSI in DEME-TFSI and poly(DEMMTFSI) composite. The concentration is defined in terms of molality $=$ (mol solute $/ \mathrm{kg}$ polymer-ionic liquid composite). The polymer concentration for the composite electrolyte was $5.4 \mathrm{wt} \%$.

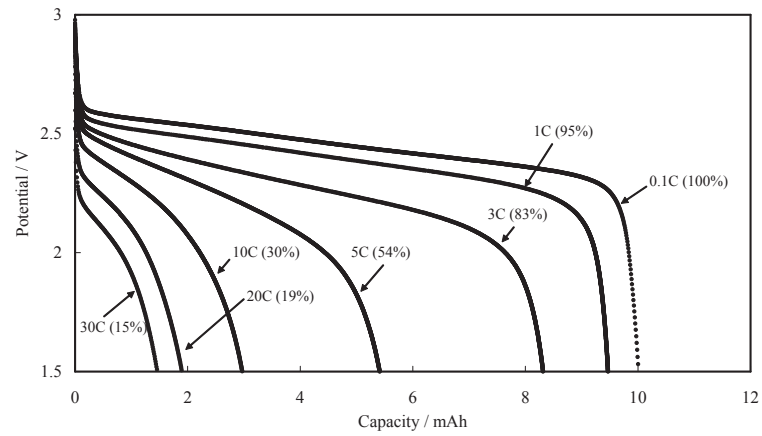

Figure 17. Discharge curves of lithium polymer cell at various current densities at $40{ }^{\circ} \mathrm{C}$. The positive electrode $=$ $\mathrm{LiMn}_{2} \mathrm{O}_{4}$; negative electrode $=\mathrm{Li}_{4} \mathrm{Ti}_{5} \mathrm{O}_{12}$; electrolyte $=1.30 \mathrm{~mol} \mathrm{~kg}{ }^{-1}$ of LiTFSI in DEME-TFSI and poly(DEMM-TFSI) composite. The concentration is defined in terms of molality $=$ ( $\mathrm{mol}$ solute $/ \mathrm{kg}$ polymer-ionic liquid composite). The polymer concentration for the composite electrolyte was $5.4 \mathrm{wt} \%$.

The discharge specific capacities and Columbic efficiency of the cell at the $1^{\text {st. }}$ was $11.8 \mathrm{mAh}$, and $82 \%$; at the second cycle, they were $11.4 \mathrm{mAh}$, and $92 \%$. After the $5^{\text {th }}$ cycle, the Columbic efficiency of this cell remained at approximately $97-98 \%$.

The battery in Fig. 17 that combined the $\mathrm{Li}_{4} \mathrm{Ti}_{5} \mathrm{O}_{12}$ anode with the $\mathrm{LiMn}_{2} \mathrm{O}_{4}$ cathode showed an excellent rate discharge character as for a lithium polymer battery. Evidently, this battery retains $83 \%$ or more of the capacity maintenance rate at a $3 \mathrm{C}$ high power discharge. Thus, it was possible to create a new, leak-free battery with a vapor-free, practical discharge performance, and a prismatic cell design by selecting an electrode material with a high speed 
charge/discharge reaction when combined with an LILP system. The rate performances of the $\mathrm{Li}_{4} \mathrm{Ti}_{5} \mathrm{O}_{12}$ negative cell and the hard carbon negative cells differ greatly, even though the electrolyte in each is the same LILP system. The interfacial compatibility of the active material and the electrolyte seem to have a bigger influence on the rate performance than the bulk ionic conductivity of the electrolyte itself. The cycling behavior of the cell, plotted in Fig. 18, indicated a good cycle durability, almost equivalent to that of a conventional lithium ion cell.

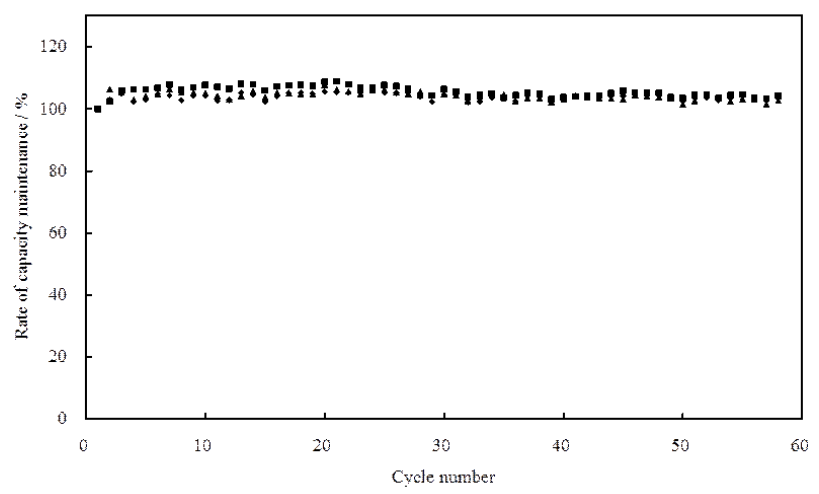

Figure 18. Cycle life of lithium polymer cell including $\mathrm{Li}_{4} \mathrm{Ti}_{5} \mathrm{O}_{12}$ as negative active material. The charge- discharge process was performed at $0.1 \mathrm{C}$ at $40^{\circ} \mathrm{C}$. The cut off voltages were $3.0 \mathrm{~V}$ and $1.5 \mathrm{~V}$. Three cells were tested.

As in the case of the hard carbon electrode, we expected that electrochemical degradation of the DEME-TFSI or poly(DEMM-TFSI) probably occurred. In our previous study, we suggested that some kinds of organic solvents, such as VC and ethylene carbonate, are effective as SEI-forming additives on the graphite used as an active material in the anode of a lithium ion cell with a binary Li-IL electrolyte. In this study, we did use a small amount of VC as a dilution solvent; however, because almost all the VC evaporates from the battery in the process of establishing the composite, it appears the small amounts of remained VC did not have large contribution to the SEI formation.

On the other hand, however, we should point out that the use of $\mathrm{Li}_{4} \mathrm{Ti}_{5} \mathrm{O}_{12}$ as the negative electrode for the lithium-ion LILP cell avoids cathodic decomposition of the LILP composite during the charge/discharge cycling.

\section{Conclusion}

This chapter has reported the synthesis and physicochemcal properties of a quaternary ammonium polymerizable ionic liquid and of the corresponding polymer. In conclusion we find; 
1. The polymerizable ionic liquid, DEMM-TFSI having a methacryl functional group as part of the ionic liquid's cation species has a remarkably low glass transition temperature $\left(T_{g}=-68^{\circ} \mathrm{C}\right)$, a relatively high ionic conductivity $\left(0.6 \mathrm{mS} / \mathrm{cm}\right.$ at $\left.25^{\circ} \mathrm{C}\right)$ and relatively wide potential windows.

2. The DEMM-TFSI monomer has a high reactivity for radical polymerization. We could prepare poly(DEMM-TFSI) with an ultra high molecular weight, with an $M_{w}$ of over one million. However, in many cases, control of the molecular weight has been difficult because of the highly reactive nature of these monomers.

3. We succeeded in achieving molecular weight control by the radical polymerization of the ionic liquid monomer via three methods; atom transfer radical polymerization (ATRP), chain transfer radical polymerization (CTRP) and reversible addition-fragmentation chain transfer polymerization (RAFT). The control of the molecular weight occurred extremely easily in CTRP because of the addition of 3-mercapto-1-hexanol as a chain transfer reagent. In RAFT polymerization, molecular weight controlled poly(IL) with a low polydispersity index can be prepared.

4. A poly-cation type material such as poly(DEMM-TFSI) has bulky tetra-alkyl ammonium functional groups in each unit and has a relatively low $T_{g}$ value due to it having a large free volume due to the effect of electrostatic repulsions of cationic groups. A polymer with a molecular weight that exceeds 100,000 has roughly a $T_{g}$ of $50{ }^{\circ} \mathrm{C}$ while, on the other hand, a polymer with $M_{n}$ about 10,000 had a 20 degrees lower $T_{g}$ of $30^{\circ} \mathrm{C}$, presumably due to the chain ends effect.

5. The bulk poly(DEMM-TFSI) has a relatively low ionic conductivity that is not practical for use in electrochemical devices at room temperature. However, the temperature dependence of the ionic conductivity showed an interesting property, unlike that of a nonionic polymer electrolyte, such as polyethylene oxide. Ionic conduction also appeared below the glass transition temperature in the polymer matrix. The anion seemed to show ionic conduction, independent of the segmental motion of the polymer chain. A new ionic conduction mechanism in the poly-cation matrix might be discovered by a further research.

6. We measured the self-diffusion coefficient value $D$ of the poly-cation, anion and solvent molecule in a high concentration solution of poly(DEMM-TFSI) by PGSE-NMR. It was clarified that the anion had a $D$ value that was comparatively close to that of the solvent molecule. We think that the anion has a high D value by escaping from a strong interaction with the poly-cation.

7. We obtained a polymer electrolyte by combining a small amount of the poly(ILs) and a binary Li-IL. The system of a lithium salt dissolved in an ionic liquid polymer and ionic liquid composite (LILP) could potentially comprise an electrolyte having zero vapor pressure. The discharge performance of a cell with an LILP system might be expected to show a poor discharge performance, because the solidified ionic liquid decreases the mobility of the ionic species. However, we have conceived a method of making a polymer battery with a practicable performance by combining electrodes that can offer a 
high-speed charge/discharge reaction. The experimental battery that combined a $\mathrm{Li}_{4} \mathrm{Ti}_{5} \mathrm{O}_{12}$ anode with a $\mathrm{LiMn}_{2} \mathrm{O}_{4}$ cathode and included an LILP electrolyte showed an excellent rate discharge character for a lithium polymer battery; at a $3 \mathrm{C}$ current rate, it retained $83 \%$ of its discharge capacity, and relatively good cycle performance. A lithium ion cell with a LILP system performed, in terms of cell performance and cycle durability, at a level of practical utility. This novel lithium polymer cell, non-flammable and leak-free, is a promising candidate as a safe, large size lithium secondary battery.

\section{Acknowledgements}

The authors thank Ms. Shoko Marukane and Mrs. Saika Honma at Tsuruoka National College of Technology for various assistance in the lithium polymer cell preparation and measurements.

\section{Author details}

Takaya Sato, Takashi Morinaga and Takeo Ishizuka

*Address all correspondence to: takayasa@tsuruoka-nct.ac.jp

Tsuruoka National College of Technology, Japan

\section{References}

[1] Rogers, R. D., \& Seddon, K. R. (2001). Ionic Liquids: Industrial Applications for Green Chemistry (Acs Symposium Series). American Chemical Society, 0-84123-789-1.

[2] Fung, Y. S. Room temperature molten salt as medium for lithium battery and alloy electrodeposition- fundamental and application. Trends Inorg Chem. (1998).

[3] Fung, Y. S., \& Zhou, R. Q. (1999). Room temperature molten salt as medium for lithium battery. J. Power Sources, 81.

[4] Caja, T. D. J., Dunstan, D. M., \& Ryan, V. (2000). P.C. Trulove (Ed.). Molten Salts XII. Pennington, NJ: Electrochem. Soc., 150.

[5] Fung, Y. S., \& Zhu, D. R. (2002). Electrodeposited tin coating as negative electrode material for lithium-ion battery in room temperature molten salt. J. Electrochem. Soc., 149, A319. 
[6] Nakagawa, H., Izuchi, S., Kuwana, K., \& Aihara, Y. (2003). Liquid and polymer gel electrolytes for lithium batteries composed of room-temperature molten salt doped by lithium salt. J. Electrochem. Soc., 150, A695.

[7] Sakaebe, H., \& Matsumoto, H. (2003). N-Methyl-N-propylpiperidinium bis(trifluoromethanesulfonyl)imide (PP13-TFSI)-novel electrolyte base for Li battery. Electrochem. Commun., 5, 594.

[8] Shin, J.H., Henderson, W.A., Henderson, W. A., \& Passerini, S. (2003). Ionic liquids to the rescue? Overcoming the ionic conductivity limitations of polymer electrolytes. Electrochem. Commun., 5.

[9] Sato, T., Maruo, T., Marukane, S., \& Takagi, K. (2004). Ionic liquids containing carbonate solvent as electrolytes for lithium ion cells. J. Power Sources, 138.

[10] Mc Ewen, A. B., Mc Devitt, S. F., \& Koch, V. R. (1997). Nonaqueous electrolytes for electrochemical capacitors: imidazolium cations and inorganic fluorides with organic carbonates. J. Electrochem. Soc., 144, L84.

[11] Mc Ewen, A. B., Ngo, H. L., Le Compte, K., \& Goldman, J. L. (1999). Electrochemical properties of imidazolium salt electrolytes for electrochemical capacitor applications. J. Electrochem. Soc., 146.

[12] Ue, M., \& Takeda, M. (2002). Application of ionic liquids based on 1-ethyl-3-methylimidazolium cation and fluoroanions to double-layer capacitors. J. Korean Electrochem. Soc., 5 .

[13] Ue, M., Takeda, M., Toriumi, A., Kominato, A., Hagiwara, R., \& Ito, Y. (2003). Application of low-viscosity ionic liquid to the electrolyte of double-layer capacitors. $J$. Electrochem. Soc., 150, A499.

[14] Sato, T., Masuda, G., \& Takagi, K. (2004). Electrochemical properties of novel ionic liquids for electric double layer capacitor applications. Electrochim. Acta, 49(2004), 3603-3611.

[15] Ohno, H., Yoshizawa, M., \& Ogiwara, W. (2004). Development of new class of ion conductive polymers based on ionic liquid. Electrochim. Acta, 50(2004), 255-261.

[16] Nakajima, H., \& Ohno, H. (2005). Preparation of thermally stable polymer electrolytes from imidazolium-type ionic liquid derivatives. Polymer, 46(2005), 11499-11504.

[17] Ogiwara, W., Washiro, S., Nakajima, H., \& Ohno, H. (2006). Effect of cation structure on the electrochemical and thermal properties of ion conductive polymers obtained from polymerizable ionic liquids. Electrochim. Acta, 51(2006), 2614-2619.

[18] Lu, J., Yan, F., \& Texter, J. (2009). Advanced applications of ionic liquids in polymer science. J. Prog. Polym. Sci., 34(2009), 431-448.

[19] Mecerreyes, D. (2011). Polymeric ionic liquids: Broadening the properties and applications of polyelectrolytes. J. Prog. Polym. Sci., 36-1629. 
[20] Yuan, J., \& Antonietti, M. (2011). Poly(ionic liquid)s: Polymers expanding classical property profiles. polymer, 52-1469.

[21] Benton, M. G., \& Brazel, C. S. (2004). An Investigation of the Degree and Rate of Polymerization of Poly (methyl methacrylate) in the Ionic Liquid 1-Butyl-3- Methylimidazolium Hexafluorophosphate. Polym. Int., 53.

[22] Sato, T., Marukane, S., Narutomi, T., \& Akao, T. High rate performance of a lithium polymer battery using a novel ionic liquid polymer composite. J. Power Sources, 164(20042007), 390-396.

[23] Yu-H, Chang., Pei-Y, Lin., Ming-S, Wu., \& King-F, Lin. (2012). Extraordinary aspects of bromo-functionalized multi-walled carbon nanotubes as initiator for polymerization of ionic liquid monomers. Polymer, 53(2012), 2008-2014.

[24] Sato, T., Morinaga, T., Marukane, S., Narutomi, T., Igarashi, T., Kawano, Y., Ohno, K., Fukuda, T., \& Tsujii, Y. (2011). Novel solid-state polymer electrolyte of colloidal crystal decorated with ionic-liquid polymer brush. Adv. Mater., 23(2011), 4868-4872.

[25] Appetecchi, G. B., Kim, G.T., montanino, M., Carewska, M., Marcilla, R., Mecerreyes, D., \& De Meatza, I. (2010). Ternary polymer electrolytes containing pyrrolidiniumbased polymeric ionic liquids for lithium batteries. J. Power Sources, 195(2010), 3668-3675.

[26] Kubisa, P. (2004). Application of ionic liquids as solvents for polymerization processes. Prog. Polym. Sci., 29(2004), 3-12.

[27] Mori, H., Yahagi, M., \& Endo, T. (2009). RAFT Polymerization of N-vinylimidazolium salt and synthesis of thermoresponsive ionic liquid block copolymers. Macromolecules, $42-8082$.

[28] Santangelo, P. G., \& Roland, C. M. (1998). Molecular weight dependence of fragility in polystyrene. Macromolecules, 31(1998), 4581-4585.

[29] Claudy, P., Letoffe, J. M., Camberlain, Y., \& Pascault, J. P. (1983). Glass transition of polystyrene versus molecular weight. Polym. Bull., 9(1983), 208-215.

[30] Teran, A. A., Tang, M. H., Mullin, S. A., \& Balsara, N. P. (2011). Effect of molecular weight on conductivity of polymer electrolytes. Solid State Ionics, 203(2011), 18-21.

[31] Hayamizu, K. (2001). Nihon-Denshi News, 33(1), 6-10, http://www.jeol.co.jp/publication/nihondenshi/j_backnumber/33/j33_all.pdf, (accessed 9 Jun 2012).

[32] Stejskal, E. O., \& Tanner, J. E. (1965). Spin diffusion measurements: spin echoes in the presence of a time-dependent field gradient. J. Chem. Phys., 42-288.

[33] Hayamizu, K. On Accurate Measurements of Diffusion Coefficients by PGSE NMR Methods -room- themperature ionic liquids- http://www.jeolusa.com/DesktopModules/Bring2mind/DMX/Download.aspx?EntryId=713\&Command=Core_Download\&PortalId=2\&TabId=337 (accessed 9 Jun) (2012). 
[34] Fuller, J., Breda, A. C., \& Richard, R. T. (1998). Ionic liquid-polymer gel electrolytes from hydrophilic and hydrophobic ionic liquids. J. Electroanal. Chem., 459.

[35] Abu-Bin, M., Hasan, S. T., Kaneko, T., Noda, A., \& Watanabe, M. (2005). Ion Gels Prepared by in Situ Radical Polymerization of Vinyl Monomers in an Ionic Liquid and Their Characterization as Polymer Electrolytes. J. Am. Chem. Soc., 127, 4876.

[36] Amine, K., Liu, J., Belharouak, I., \& Park, S. H. (2006). Proceedings of advanced technology development review meeting at Sandia National Laboratory. Carlsbad, NM, USA.

[37] Holzapfel, M., Jost, C., \& Nov'ak, P. (2004). Stable cycling of graphite in an ionic liquid based electrolyte. Chem. Commun. 
